\title{
A CONCEPÇÃO DO I SARAU DAS POÉTICAS INDÍGENAS POR UMA ANTROPÓLOGA-ESCRITORA
}

\author{
DEBORAH GOLDEMBERG ${ }^{1}$ \\ UNIVERSITY OF LONDON
}

\begin{abstract}
RESUMO: Adotando a abordagem da antropologia interpretativa, o artigo narra a experiência de uma antropóloga-escritora no contato com o universo da literatura e poesia indígena no Brasil, que a inspirou a conceber o I Sarau das Poéticas Indígenas, da Casa das Rosas, como um evento para reunir índios, escritores indígenas e indianistas de diversas origens, clássicos e contemporâneos. Discute a questão da função social da poesia \& prosa, sua independência do contexto cultural e conclui por falar de "poéticas", pois não cabe apenas uma única poética, a ocidental, aristotélica, e sim a diversidade delas que vive na história oral e no ritual indígena, elaboradas ou não, tendo todas em comum a inventividade e o encantamento com a palavra e suas possibilidades.
\end{abstract}

PALAVRAS-CHAVE: poética; poesia; embeddedness; indígena.

ABSTRACT: Adopting the interpretative anthropology approach, the text narrates the experience of an anthropologist-writer in contact with the universe of Brazilian indigenous literature and poetry, which inspired her to conception of the I Recital of the Indigenous Poetics of the Casa das Rosas, as an event to assemble Indians, indigenous and indianist writers from different backgrounds, both classic and contemporary. It discusses the issue of the social function of poetry \& prose and its independence from cultural context and concludes for talking of "poetics", because the event will not host on one only poetic, western Aristotelean poetic, but the diversity that inhabits oral history and indigenous rituals, whether elaborated or not, which have in common the inventiveness and enchantment with words and their possibilities.

KEYWORDS: poetics; poetry; embeddedness; indigenous.

\section{Introdução}

\footnotetext{
1 Deborah Goldemberg é formada em Antropologia Social e Direito, pela London School of Economics/University of London, e mestre em Estudos de Desenvolvimento pela mesma faculdade. Tem doze anos de carreira em desenvolvimento local sustentável, tendo trabalhado em agências da ONU (Organização das Nações Unidas), SEBRAE e IFC (International Finance Corporation)/Banco Mundial no Brasil e em países da América Latina. Desde 2008, dedica-se a literatura, tendo publicado textos pelo Selo Demônio Negro/Annablume, Editora Andross e Guemanisse; foi curadora do I Sarau das Poéticas Indígenas da Casa das Rosas/Governo de SP; atua também como consultora na área de desenvolvimento.
}

Espaço Ameríndio, Porto Alegre, v. 3, n. 1, p. 42-60, jan./jun. 2009. 
DEBORAH GOLDEMBERG - A concepção do I Sarau das Poéticas Indígenas ...

Sei que todo artigo acadêmico começa com uma introdução ao tema e estabelece referenciais teóricos, mas há tempos não sou isso, acadêmica, se é que algum dia eu fui. Quando estive mais perto de o ser, ainda na época da faculdade, incomodava-me a esterilidade das normas. Acredito que devemos pousar a caneta no papel (ou os dedos no teclado) somente quando o coração bate forte ou quando a mente inquieta não nos deixa descansar a cabeça no travesseiro. Peço ao leitor, desde já, perdão pelas minhas inconformidades.

Sou formada em Antropologia Social pela London School of Economics e sou, essencialmente, antropóloga no meu jeito de ver o mundo. De tudo o que li na minha graduação, o que mais apreciei foi Geertz (1973), porque ele encerrou de forma criativa o debate introspectivo e exaustivo da teoria antropológica contemporânea sobre a relação sujeito \& objeto e a legitimidade do saber antropológico. Declarando que a nossa disciplina não é mesmo uma ciência e o que pode um antropólogo é escrever um "texto" sobre um grupo social distinto do seu, interpretando-o, e ser transparente quanto ao viés interpretativo que sua própria formação cultural implica, eu vislumbrei uma saída. Não sei se entendi corretamente tudo o que ele disse, mas sei que achei aquilo libertador e por isso concordei. Já fazia alguns anos que os diplomas de Antropologia da minha universidade eram dados com bacharelados em artes (B.A.), ao invés de ciências (B.Sc.). Portanto, eu alegremente me graduei antropóloga-artista, interessada no outro, com uma "paixão pela diferença", como é o título de um dos livros de minha professora favorita (MOORE, 1994).

O que pretendo com este artigo é escrever um texto interpretativo sobre o universo da literatura e poesia indígena brasileira, o qual tive a oportunidade de "ler" durante o período de janeiro a abril de 2009, em que concebi o evento I Sarau das Poéticas Indígenas da Casa das Rosas², ocorrido em 19 de abril de 2009, no papel de curadora. Vale dizer que serei também participante do evento, como escritora, portanto sou objeto e sujeito da história que narro, ou seja, sou autora e narradorpersonagem deste texto que escrevo.

\footnotetext{
${ }^{2}$ A Casa das Rosas, Espaço Haroldo de Campo de Poesia e Literatura, Secretaria da Cultura do Estado de São Paulo.
} 
DEBORAH GOLDEMBERG - A concepção do I Sarau das Poéticas Indígenas ...

Para cumprir a norma do paradigma que adotei, falarei ao leitor dos aspectos mais relevantes de minha formação cultural. Assim, poderá mais facilmente deduzir algumas de minhas interpretações, justificando-as ou deixando de concordar com elas.

Sou uma mulher nascida em São Paulo, em 1975, filha de pai gaúcho, professor universitário, e mãe fluminense. Tenho três irmãos mais velhos. Minha família nuclear é de classe média urbana, medianamente intelectualizada. Tenho ascendência judaica por parte de pai, que é ateu, e por parte de mãe sou católica batizada, nãopraticante, frequentadora de centros espíritas e, ocasionalmente, terreiros de candomblé, ou seja, sincretismo total. Aos 23 anos, me converti ao judaísmo formalmente e casei-me numa sinagoga. Após meu divórcio, distanciei-me do judaísmo, tenho fé em Deus, mas quando penso racionalmente no assunto sou agnóstica. Aos trinta e poucos anos, fiz a árvore genealógica de minha mãe e descobri que minha tataravó era índia. Por circunstâncias históricas da minha família, tive oportunidade de viajar largamente pelo mundo e realizar meus estudos na Inglaterra. Após concluir meu mestrado em Estudos de Desenvolvimento, também na London School of Economics, trabalhei durante dez anos com antropologia aplicada em projetos de desenvolvimento sustentável e avaliação de impacto social de projetos de desenvolvimento em comunidades tradicionais, indígenas e quilombolas no Norte e Nordeste do Brasil. Aos 33, decidi dedicar-me à literatura. Tenho crônicas e poemas publicados em coletâneas, um livro chamado Ressurgência Icamiaba, mantenho um blog literário e escrevo para o projeto de blogueiros internacionais Global Voices.

\section{Encontro com a poesia indígena}

Tudo começou ao acaso, como muitas das coisas boas que acontecem na vida. Em 2007, eu resolvi fazer um curso de introdução à poesia na Casa das Rosas, localizada num dos belíssimos casarões antigos que sobraram na Avenida Paulista.

O professor era o poeta Claudio Daniel, nascido em 1962, magro, irônico e budista, como ele próprio se descreve. O rumor nos bastidores 
DEBORAH GOLDEMBERG - A concepção do I Sarau das Poéticas Indígenas ...

do curso era de que ele é o grande nome da poesia neobarroca no Brasil hoje. Começou o curso dizendo que poesia é paixão pela linguagem e sua relação estética com os sons, as cores e as formas. Na sua visão, enquanto a linguagem pode ter a função de transmissão de conteúdo, como num artigo científico, ou emotiva, como numa carta de amor, a função da linguagem na poesia é puramente estética.

Alguns participantes logo o questionaram, citando Maiakovski ${ }^{3} \mathrm{e}$ Homero ${ }^{4}$ como exemplos de que a poesia pode também ter função social ou histórica. Claudio Daniel fez uma leve concessão dizendo que os grandes poetas, às vezes, conseguem reunir as diversas funções da linguagem numa obra. No entanto, advertiu-nos que as "ideias são perigosas para a poesia", já que esta naturalmente aproxima-se das artes plásticas e da música.

Para aprofundar esse "conceito" nas nossas cabeças, ele nos passou o seguinte dever de casa: escrever três versos - um inspirado em música, outro em imagens e outro em ideias.

Chegando em casa, nos cinco minutos que tinha antes de cair no sono, fiquei pensando em sons poéticos que pudessem me ajudar na primeira tarefa e logo me vieram sons de palavras indígenas, provavelmente oriundas de algum laudo antropológico que eu andara lendo naqueles dias. Escrevi um verso bobo e o sono me venceu antes que eu pudesse pensar em outro:

Naviraí és sede do povo Tupi

Cacique Chuí receberá te aqui.

Para minha surpresa, quando recitei o verso na aula do dia seguinte, os olhos de Claudio Daniel se maravilharam. Disse-me que a grande lacuna da poesia brasileira é a poesia indígena: "Precisam captar a poesia indígena brasileira!". Quando ele descobriu que eu era antropóloga então, esfuziou-se: "Vamos fazer isso juntos?". Eu concordei, em termos gerais, sem jamais pensar no que aquele breve curso de poesia teria como consequência.

\footnotetext{
${ }^{3}$ Poeta russo, 1893-1930, considerado o poeta da revolução russa.

${ }^{4}$ Poeta grego, teria vivido no Século VII a.C, escreveu os épicos clássicos $A$ Ilíada e $A$ Odisséia.
} 


\section{Programa de Índio}

O tempo foi passando e, ocasionalmente, eu encontrava Claudio Daniel nos eventos literários da cidade. Cumprimentávamo-nos e ele sempre dizia: "Precisamos fazer algo sobre a poesia indígena". Eu respondia, como o fazem os paulistanos: "Precisamos, sim!" - sem vislumbrar maiores consequências.

Um belo dia, Claudio Daniel tornou-se Coordenador Cultural da Casa das Rosas. Isso significou que ele estava na direção do maior centro cultural do Estado de São Paulo dedicado exclusivamente à literatura. Não passou muito tempo e ele me chamou para conversarmos sobre a organização de um sarau indígena, que ele informalmente passou a chamar de "Programa de Índio".

No dia 5 de janeiro de 2009, bem antes do carnaval, quando o ano de fato começa no Brasil, Claudio e eu nos reunimos no charmoso café localizado atrás da Casa das Rosas para falarmos do Sarau Indígena. Foi uma reunião rápida e tensa, algo que eu não esperava. Ele me pediu para eu montar um projeto para o Sarau Indígena e enviar para ele o mais breve possível.

Agarrei a oportunidade e o fiz imediatamente. Uma semana depois, o projeto estava na mão dele. Dois dias depois, no entanto, recebi um e-mail dele dizendo que fora demitido da Casa das Rosas. Entendi então a razão de seu nervosismo naquele dia temporão de 2009.

\section{Sarau de Poesia Indígena}

Meu desapontamento durou apenas alguns dias, porque outra poeta que eu desconhecia até então, Tatiana Fraga, entrou no lugar de Claudio Daniel e, sob gentil recomendação dele, resolveu levar o projeto adiante. Imediatamente entrei em contato com ela e marcamos uma reunião. Tatiana adorou o projeto e me deu a honrosa tarefa de ser a curadora do evento.

A primeira coisa que eu fiz foi tirar o tom pejorativo do títulotrocadilho que Claudio Daniel vinha dando, com a melhor das intenções, 
DEBORAH GOLDEMBERG - A concepção do I Sarau das Poéticas Indígenas ...

ao evento. "Programa de índio cairá mal entre os índios", eu disse à Tatiana, "pois estamos falando de um sarau de poesia e prosa indígena". O que exatamente eu tinha em mente?

\section{1. Índios aldeados}

No início, eu pensava em trazer índios aldeados de várias regiões do país para apresentarem manifestações culturais marcantes que se utilizassem da linguagem de forma elaborada, fosse em letras de cânticos ou enredos de contação de histórias.

Pensei nos Guarani de São Miguel das Missões e na sua fabulosa tradição musical, que eu conhecera numa visita ao Rio Grande do Sul. A experiência das Missões Jesuíticas do século XVII, reduções cristãs criadas nas fronteiras do Brasil com a Argentina e o Paraguai, deram margem a uma troca cultural inusitada, pois a arte e a música eram altamente valorizadas por ambas as culturas, o que ajudou na sua aproximação e convivência, apesar de ela não ter sido sempre pacífica. Quando eu estive lá, visitei uma aldeia e vi um índio tocando um violino apoiado no antebraço e cantando cânticos de resistência. Ele me disse: "Os brancos é que trouxeram o violino, mas nós o tocamos do nosso jeito".

Cântico da Aldeia Tekoa Kòènju, de São Miguel das Missões ${ }^{5}$ :

oreruvixa karai seppé/nosso chefe sepé Tiraraju
orereja ore yvypyae/nos deixou a nossa própria terra
ojujuka mavy ndaje/quando ele foi morto, se diz
taba porá gue i taba porá gue/(deixou) os belos povos
que já não são (as ruínas bonitas).

Pensei também nos índios Pataxó que eu conhecera no Sul da Bahia. Os Pataxó são o povo que travou o primeiro contato com os portugueses na região de Porto Seguro há 509 anos. Sua trajetória é admirável e demonstrativa de grande adaptabilidade frente às adversidades, além de capacidade de união em prol da defesa de seus direitos e resistência cultural. Hoje, com parte de suas terras

\footnotetext{
${ }^{5}$ Disponível no CD Tekoa Kõenju, da Aldeia Alvorecer, projeto da Associação Consciência Guarani.
} 
DEBORAH GOLDEMBERG - A concepção do I Sarau das Poéticas Indígenas ...

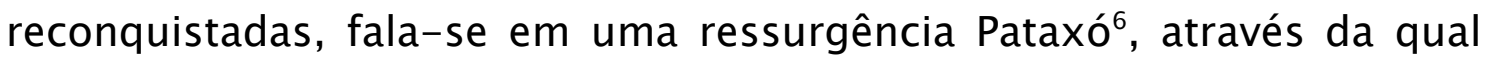
índios idosos e jovens buscam resgatar sua cultura ancestral e reviver sua língua nativa. Em Porto Seguro e mais ao sul da Bahia, visitei diversos grupos Pataxó e presenciei alguns ritos em que eles cantam cânticos em patxôhã, linguagem de guerreiro, que eles estão revivendo.

\author{
Kanã pataxi pataxó \\ (de Tapurumã Pataxó) \\ Awê kanã, kanã pataxi \\ Awê, awê Kanã, Kanã pataxi \\ Keytxé poytãg masaká \\ Keytxé cocá, lança maracá \\ Apoykxay agoyspã \\ Txuhap suniatá, hamei, hamiá.
}

Além desses dois grupos, o Sarau não poderia deixar de ter uma representação amazônica, onde vive a maior parte dos índios brasileiros. Buscando identificar "índios-poetas", como os denominei abstratamente, entrei em contato com amigos índios da Amazônia e colegas de ONGs e movimentos sociais atuantes na área indígena. No entanto, essa estratégia provou-se pouco promissora. Ninguém conseguia pensar em "índios-poetas", o que achei estranho já que todos tinham uma rede social ampla no meio.

Postulei que o problema talvez estivesse na denominação "índiopoeta" que eu utilizava na minha busca. Recordei-me do conceito de embeddedness, que eu estudara na faculdade, do substantivismo da obra de Polanyi (apud DALTON, 1971), de que em comunidades préindustriais todas as facetas da vida estão imersas (ou embedded) no seu sentido social mais amplo. No contexto das comunidades tradicionais amazônicas, pensei, a poesia está embedded em outras facetas da vida social e, portanto, a figura do "poeta" não devia fazer sentido para eles. O "índio-poeta", aquele com o domínio das letras que eu buscava, seria um pajé, um cacique ou um velho contador de histórias.

\footnotetext{
${ }^{6}$ Termo cunhado por Pedro Agostinho, da UFBA, na RBA (Reunião Brasileira de Antropologia), da ABA (Associação Brasileira de Antropologia), 2008.

${ }^{7}$ Disponível no CD Õ Homãk Patxitxiá Mapa, produzido pelo Grupo Filhos da Natureza, da aldeia sede Bacumuxá, $\mathrm{MG}$ - sem tradução para o português.
} 
DEBORAH GOLDEMBERG - A concepção do I Sarau das Poéticas Indígenas ...

Tentei explicar aos colegas que eu não buscava "poetas profissionais", mas sim poetas no contexto indígena, ou seja, índios que utilizassem a linguagem de forma mais elaborada do que o usual, fosse na música, nos rituais religiosos ou na contação de histórias. Mesmo assim, o convite teve pouca ressonância.

Percebi que era por eu já conhecer os Guarani e os Pataxó que o convite para eles dera certo, pois ele já partira da minha leitura de onde residia a poesia na sua cultura.

A estratégia de trazer índios aldeados de várias partes do Brasil também se fragilizou quando comecei a estimar os custos de trazê-los para São Paulo, que seriam altíssimos, além das dificuldades que eu enfrentaria em obter autorizações da Funai.

\section{Literatura indígena}

Num momento de desespero, em que comecei a pensar que não conseguiria trazer quase ninguém para o Sarau Indígena, mirava a tela do computador com o olhar perdido e acabei recorrendo ao "santo Google de todas as causas", colocando o termo "literatura indígena" no motor de busca e clicando. Eis a grande surpresa que eu tive: descobrir que existe um grande movimento na internet de escritores indígenas com websites próprios e até bilíngues (de línguas estrangeiras, como o italiano), blogues e até comunidades no Orkut com milhares de fãs! Fiquei encantada e comecei a tentar entender quem eram aquelas pessoas. Eram índios mesmo? Eram mestiços? Eram aldeados? Viviam nas cidades? Através dos contatos deles, disponíveis na internet, fui conhecendo um a um e descobri que eles são tudo isso!

Daniel Munduruku talvez seja o autor de maior expressão deste grupo. É originário do Estado do Pará e vive em São Paulo, onde é doutorando em Educação pela USP. Em um artigo disponibilizado online (MUNDURUKU, 2008), ele explica a proposta do seu grupo literário. Em primeiro lugar, reitera que a tradição indígena é a oralidade e argumenta que isto é um ato de priorização, já que, para as comunidades indígenas, o que importa é o exercício da memória e a

\footnotetext{
${ }^{8}$ www.google.com .
}

Espaço Ameríndio, Porto Alegre, v. 3, n. 1, p. 42-60, jan./jun. 2009. 
DEBORAH GOLDEMBERG - A concepção do I Sarau das Poéticas Indígenas ...

renovação dela, o que só é possível enquanto usa-se um meio flexível como a linguagem falada. A rija escrita, preferida pelos ocidentais por causa da permanência que ela proporciona, é vista por alguns índios como algo que contradiz a tradição da oralidade. Munduruku, no entanto, sai em defesa contundente da incorporação da técnica ocidental pelos indígenas:

É preciso conhecer. É preciso se tornar conhecido. É preciso escrever - mesmo com tintas do sangue - a história que foi tantas vezes negada. A escrita é uma técnica. É preciso dominar esta técnica com perfeição para poder utilizá-la a favor da gente indígena. Técnica não é negação do que se é. Ao contrário, é afirmação de competência. É demonstração de capacidade de transformar a memória em identidade, pois ela reafirma o Ser na medida em que precisa adentrar no universo mítico para dar-se a conhecer ao outro (MUNDURUKU, 2008, p. 1).

O posicionamento de Munduruku orienta a sua prática como escritor e líder do Inbrapi (Instituto Indígena Brasileiro para Propriedade Intelectual). Preocupa-o não só o enfrentamento cultural, mas também o aproveitamento das oportunidades materiais, que surgem da demanda mundial pela literatura indígena. Junto com outros autores indígenas, como Olívio Jekupé, Eliana Potiguara, Marcos Terena e outros, organizase para esta batalha.

Incluí-os na programação do Sarau me guiando pelo critério de autodeclaração, uma vez que eles se autodenominam escritores e poetas de literatura indígena, de acordo com a Convenção 169 da Organização Internacional do Trabalho, que rege e orienta a relação com povos indígenas de todo o mundo.

\section{Literatura indianista}

Já estava mais tranquila tendo descoberto o movimento da literatura indígena, quando lia o jornal de domingo e deparei-me com um artigo do antropólogo Pedro Cesarino no caderno Aliás, do jornal $O$ Estado de S. Paulo (18/01/2009), que chamava a atenção para a 
DEBORAH GOLDEMBERG - A concepção do I Sarau das Poéticas Indígenas ...

"negligência sistemática em relação à poesia produzida por povos indígenas das Américas" (CESARINO, 2009). Li-o com atenção, pois ele reiterava o argumento de Claudio Daniel sobre a falta de reconhecimento da poesia indígena no Brasil. Além disso, falava de seu trabalho de transcrição de cantos de índios semi-isolados, os Marubo, do Estado do Amazonas.

Em meio ao seu argumento central, Pedro chamou a atenção para o fato de que diversos autores brancos ou mestiços, desde o próprio Padre Anchieta, vêm reinventando e metamorforizando as culturas indígenas em suas obras. Citou Sousândrade, do século XIX, e os modernistas Mário de Andrade, Oswald de Andrade e Raul Bopp, do século XX. Vieram-me em mente outros autores como Gonçalves Dias e José de Alencar, século XIX, que foram e são ainda responsáveis pela constituição do imaginário que o brasileiro tem do índio. Logo pensei: "Eles também não podem faltar".

No mesmo caderno, Sérgio Medeiros, professor de literatura da UFSC, citou a obra do escritor contemporâneo Douglas Diegues (que escrevera o prefácio do meu próprio livro Ressurgência Icamiaba, uma novela multiétnica e transbrasileira, baseada em lendas amazônicas) e seus esforços de valorização da linguagem indígena, como no livro Kosmofonia Mbya Guarani (DIEGUES e SEQUERA, 2006). Sua obra revela a continuidade de uma literatura indianista que recorre ao multilinguismo e inspira-se em lendas e ritos indígenas. $\mathrm{Na}$ introdução do livro Kosmofonia Mbya Guarani, Diegues diz:

Bocê vai ouvir u habla selvagem de Ñande Chy, la xamãna que vivia em Isla Filomena, e vai descobrir que us Mbyá-Guarani ainda non conhecem la linguagem poética porque ellos nunca conheceram otra linguagem que non fosse la linguagem poética (DIEGUES e SEQUERA, 2006, p. 4).

A linguagem por ele utilizada é o portuñol selvagem (ou portunhol salbaje), algo como um primo moderno do proibido nheengatu, que em suas palavras é,

U portunhol salbaje es la lingua falada en la frontera du Brasil com u Paraguai por la gente simples que increiblemente sobrevive de teimosia, brisa, amor al 
DEBORAH GOLDEMBERG - A concepção do I Sarau das Poéticas Indígenas ...

imposible, mandioca, vento y carne de vaca. Es uma lengua bizarra, transfronteriza, rupestre, feia, bella, diferente. Pero tiene una graça salvage que impacta(DIEGUES, 2009 - on line).

Tive a certeza de que esses escritores todos, os clássicos e contemporâneos, tinham de participar do Sarau, porque eles são pilares do diálogo intercultural no qual vive hoje o índio brasileiro. Com a cabeça absolutamente repleta de ideias, enfurnei-me na biblioteca da Casa das Rosas, que abriga os 20.000 livros que um dia pertenceram ao poeta Haroldo de Campos, crítico literário que foi sensível à literatura indianista brasileira, para aprofundar-me nesta literatura. Resolvi priorizar os seguintes autores para o sarau: Padre Anchieta (século XVI), Gonçalves Dias, José de Alencar e Sousândrade (século XIX), Raul Bopp, Mário de Andrade e Oswald de Andrade (século XX) e Douglas Diegues, seguido de mim mesma e Pedro Tostes, o poeta maloqueirista índiodescendente (século XXI).

\section{4. Índios imigrantes}

Ainda batalhando para trazer índios aldeados para o Sarau, deparei-me com o fenômeno dos índios imigrantes, originários de várias regiões do país e que vivem em São Paulo. Isso deu-se através de contatos com a Professora Luciana Storto, da FFLCH/USP, que indicoume o índio-descendente João Paulo Ribeiro, filho de um índio Kaingang com uma italiana, aluno de linguística da USP e atuante no movimento indígena paulista. João me apresentou diversos colegas indígenas e me levou até Benedito Prezia, da Pastoral Indigenista de SP, que é antropólogo e escritor de diversos livros sobre índios, inclusive um que é dedicado ao tema de índios urbanos (PREZIA, 2001).

Através desses contatos, que se tornaram praticamente colegas de curadoria, descobri o universo dos índios imigrantes. Alguns deles, como os Pankararu, vieram para São Paulo, em suas próprias palavras, "num pau de arara fugindo da seca, das invasões de suas terras, em busca de novas alternativas". Vivem hoje numa "aldeia urbana" dentro de uma favela no Parque Real, na Zona Sul de São Paulo. Outros vivem 
DEBORAH GOLDEMBERG - A concepção do I Sarau das Poéticas Indígenas ...

fisicamente dispersos na cidade, tendo vindo da Amazônia e várias partes do Cone Sul para estudar ou trabalhar. Mantêm laços sociais fortes com outros índios de sua etnia (e outras) através de associações indígenas, centros culturais ou de saúde. O que todos eles têm em comum é que nasceram em aldeias na sua região, e, com a imigração, tiveram o seu meio de vida alterado e passaram a manter um alto grau de contato com a sociedade nacional e a cultura ocidental. Apesar disso, sua identidade indígena continua sendo central, tanto no plano pessoal quanto profissional.

Achei interessante incluir no Sarau a poesia e prosa, que é mantida ou surge neste processo de alta interculturalidade em que vivem os índios imigrantes de São Paulo. Assim, convidei representantes dos Pankararu, Baniwa, Mura e Guaranis para o Sarau.

\section{Quatro grupos dos quatro cantos do país}

A esta altura da minha pesquisa, eu estava convencida de que o Sarau Indígena deveria reunir representantes dos quatro grupos que eu havia identificado ao longo da minha interação com índios, escritores indígenas, acadêmicos e ativistas, sendo que uma representação regional, focando as regiões Norte, Nordeste, Sul e Sudeste também foi também almejada:

- Os índios (aldeados ou não, cuja poesia surge no âmbito da sua tradição cultural, seja através de cânticos, rituais, seja na educação dos mais jovens etc.).

- Os índios imigrantes (aldeados ou não, cuja poesia surge no âmbito da interculturalidade, mesclando elementos da sua tradição cultural e da cultural ocidental).

- Os escritores indígenas, urbanos, profissionais, com livros publicados

e traduzidos, equipados da tecnologia ocidental para o registro e disseminação da sua cultura indígena.

- Os escritores indianistas, clássicos ou contemporâneos, que se inspiram em lendas ou linguagem indígena para escrever sobre o contato e sobre o Brasil mestiço. 
DEBORAH GOLDEMBERG - A concepção do I Sarau das Poéticas Indígenas ...

\section{Sarau das Poéticas Indígenas}

Tendo identificado tantas vertentes de literatura indígena e indianista, Tatiana Fraga e eu já estávamos muito entusiasmadas com o evento e começamos a fazer contato com diversas instituições em busca de patrocínio.

Para nossa surpresa, deparamo-nos com uma voz de dissidência. Ao convidarmos certo grupo ${ }^{9}$ para participar do Sarau, uma senhora nos disse: "Do que vocês estão falando? Não existe poesia indígena, nem literatura indígena! Poesia e literatura são coisas da tradição ocidental, aristotélica. Vocês não sabem do que estão falando!".

Seu eu tivesse um doutorado em literatura indígena, saberia como responder embasada em argumentos teóricos. Como não tenho, ouvi-a falando exaltada enquanto minha mente visualizava os livros de Daniel Munduruku e seu grupo, os cantos xamanísticos transcritos dos Marubo e os Pataxó cantando no entorno da fogueira. Pensei em como essas manifestações culturais são inegavelmente imbuídas daquilo que nós ocidentais chamamos de poesia e prosa, porque impressionam nelas a eloquência e o ordenamento original das palavras. Suas histórias são criativas, repletas de personagens curiosos e surpreendentes. Seus versos despertam no interlocutor o sentimento do belo ("que bonito", exclamam os ouvintes) e comovem. Naquele momento, intuitivamente, não tive dúvida de que as manifestações dos índios têm em comum com a poesia e literatura ocidental o encantamento com a palavra e todas as suas possibilidades. Abusando do mesmo procedimento, compus um trocadilho: se o que os índios fazem é poesia eu não sei, mas que tem poesia no que eles fazem, isso tem!

Mesmo assim, quando desliguei o telefone com a tal senhora exaltada, ainda com a orelha vermelha e quente, revolvi pesquisar melhor o tema. Mergulhei em Aristóteles, nos mitos gregos, no berço da civilização ocidental, ou seja, no cronotopo do nascimento do conceito de poética e literatura, isto é, no início dos estudos e normatização da versificação.

\footnotetext{
${ }^{9}$ Como este incidente gerou conflitos institucionais, eu não contarei detalhes das pessoas e organizações envolvidas, mas o conteúdo do conflito é muito interessante e por isso incluo-o aqui.
}

Espaço Ameríndio, Porto Alegre, v. 3, n. 1, p. 42-60, jan./jun. 2009. 
DEBORAH GOLDEMBERG - A concepção do I Sarau das Poéticas Indígenas ...

A Poética Clássica, de Aristóteles (384-322 a.C.), foi escrita quando a mitologia da Grécia Antiga, com seus deuses e deusas, heróis e heroínas, ainda fazia parte da cultura pagã que antecedeu a conversão dos gregos ao cristianismo. Ou seja, a poesia surgiu em um ambiente muito semelhante ao que vemos hoje nas culturas tradicionais ameríndias. A poesia/prosa era embedded na cultura tradicional grega, mantida na tradição oral e existia com uma função de ordem cosmológica, pedagógica e cultural. Foi só com a chegada do cristianismo que a mitologia grega foi arrancada de sua função social e religiosa (BRANDÃO, 1997), ou disembedded, e tornou-se estritamente ficção, poesia ou literatura, com função primeiramente estética.

Naquela época de culto à razão, intrigava aos filósofos a possibilidade do descolamento da linguagem do contexto social, este conceito da linguagem per se, independente ou desafiadora da cultura, com função puramente estética. Havia reconhecimento de que a retórica e as técnicas de linguagem têm um poder de encantar um interlocutor a ponto de criar novas realidades e não só retratar e manter a ordem vigente. Platão, que viveu 400 a.C., cobrava de seus poetas uma postura ética a ponto de expulsar das cidades gregas aqueles que desobedeciam esta regra. Para entender melhor o fenômeno (ou talvez melhor controlá-lo?), vários filósofos dedicaram-se à análise das características das narrativas poéticas, tal como a verossimilhança, a concisão, a contundência, a metrificação, os gêneros, a catarse, a mimese etc. Assim constitui-se a poética clássica que tornou-se o marco zero da literatura ocidental.

Não há dúvida de que a maioria dos índios das Américas não travaram contato significativo com a poética clássica grega e, portanto, não compartilham desta tradição. No entanto, seria essa constatação suficiente para descartarmos os conceitos de poesia e literatura indígena nas Américas?

Parece-me que o fato de comunidades indígenas mais isoladas não terem conhecimento da poética aristotélica, ou não terem redigido uma poética própria normatizando a sua poesia e prosa, não significa que ela não tenha valor poético e as mesmas características que instigaram os filósofos gregos a estudarem a sua. 
DEBORAH GOLDEMBERG - A concepção do I Sarau das Poéticas Indígenas ...

Outro ponto importante: apesar de que, desde o Romantismo, a arte vem se dissociando cada vez mais de uma função social, como disse o poeta Claudio Daniel em seu curso de poesia, isso é um tema de grande oscilação pendular ao longo da história (BRANDÃO, 1997). Como o grupo de poetas aprendizes corretamente questionaram o professor Daniel naquela primeira aula de poesia na Casa das Rosas, houve, mesmo no século XX, forte oposição ao conceito de arte estar dissociada de função social e contexto cultural. Cito a título de exemplo a primeira regra da poética de Maiakovski (MAIAKOVSKI, 1977), no início do século $\mathrm{XX}$ :

Quais são, pois, os dados indispensáveis ao início do trabalho poético? Primeiro: a existência, na sociedade, de um problema cuja solução só é concebível por uma obra poética - o mandato social (MAIAKOVSKI, 1977, p. 21).

Em outras palavras, Maiakovski pregou no século XX a poesia embedded no contexto sociocultural, assim como ela era na Grécia Antiga e assim como ela é entre os índios da América até hoje - parte intrínseca da vida social.

Ou seja, ao entendermos que a dissociação da poesia ou da prosa de uma função social não é condição para qualificar o uso elaborado da linguagem (oral ou escrita) como arte poética, podemos concluir que a poesia e a prosa indígena estão de igual para igual com a poesia e a prosa ocidental.

No entanto, pensando como curadora, achei que, mais do que defender a minha interpretação sobre o tema da literatura indígena, o Sarau deveria expor estas diversidade de ideias e argumentos para instigar um debate acerca do tema.

Cheguei à conclusão de que o Sarau Indígena devia chamar-se I Sarau das Poéticas Indígenas, para contemplar as várias práticas poéticas que coexistem no território brasileiro, tanto a de origem grega, fundadora da cultura ocidental colonizadora, como as poéticas não escritas, onde reina a poesia pura, no sentido de manuseio da linguagem humana para além da produção do real, em geral direcionada para funções culturais diversas, sejam elas cosmológicas, educacionais, 
DEBORAH GOLDEMBERG - A concepção do I Sarau das Poéticas Indígenas ...

pedagógicas ou bélicas, sejam elas conscientes de serem isso, poéticas, ou não.

\section{Em suma}

A partir do convite para realizar a curadoria de um sarau indígena, iniciei o contato com o universo da poesia e literatura indígena brasileira, o qual narrei no artigo acima.

Minha grande descoberta foi perceber que além dos índios aldeados e imigrantes, com suas manifestações culturais tradicionais e interculturais, e os escritores indianistas, há um grupo organizado de escritores e poetas indígenas profissionais no Brasil.

Sobre a dissidência da existência ou não de uma poesia e literatura indígena, identifiquei dois pontos importantes: (i) que o fato de os índios das Américas nem sempre conhecerem a poética clássica não quer dizer que eles não façam poesia e prosa, pois a poética clássica é a normatização da poesia grega antiga que já existia antes, ou seja, a poesia precede a poética, (ii) o fato de os índios das Américas terem sua poesia e prosa imersa do contexto cultural, atuando em função religiosa ou cosmológica, não quer dizer que eles não façam poesia e prosa, pois a poesia grega antiga era também isso. Sendo assim, conclui que estamos falando de poéticas diversas, algumas normatizadas e outras livres nos cânticos e enredos dos contadores de histórias - fenômenos da mesma natureza.

Mesmo assim, como o I Sarau das Poéticas Indígenas é uma reunião plural, optei por deixar o espaço aberto para a diversidade de vozes e visões sobre poesia e prosa indígena, na voz dos índios, os escritores indianistas e dos críticos deste conceito.

\section{A realização I Sarau das Poéticas Indígenas}

Tendo apresentado como formulei a conceituação do I Sarau das Poéticas Indígenas, eu abri o palco para os índios e escritores falarem por si só e a platéia formular suas próprias opiniões. Como boa 
DEBORAH GOLDEMBERG - A concepção do I Sarau das Poéticas Indígenas ...

novelista, termino este artigo por aqui, anunciando que haverá outro em que eu pretendo compartilhar os textos apresentados e descrição das manifestações culturais que foram apresentadas pelos participantes do I Sarau das Poéticas Indígenas de 19 de abril de 2009, além de produzir um "texto" sobre o seu significado.

\section{Lista completa dos participantes do I Sarau das Poéticas Indígenas, com breve biografia:}

\section{A poética dos índios aldeados}

- Os Pataxó do Sul da Bahia: Sr. Zé Fragoso ${ }^{10}$.

- O antropólogo Pedro Cesarino fala sobre os índios Marubo ${ }^{11}$.

\section{A poética dos índios imigrantes}

- Os Pankararu: Sr. Bino Pankararu ${ }^{12}$.

- Os Baniwa: Eurico Baniwa ${ }^{13}$.

- Os Mura: Juju Mura14.

- Os Guarani: Poty Porã ${ }^{15}$ e Emerson de Oliveira ${ }^{16}$.

\section{A poética dos escritores indígenas}

\footnotetext{
${ }^{10}$ Sr. Zé Fragoso é trovador e cacique da aldeia da Aldeia Tibá, no Prado.

${ }^{11}$ Pedro Cesarino é graduado em Filosofia pela USP (Universidade de São Paulo), e mestre e doutor em Antropologia Social pelo Museu Nacional (UFRJ). Especialista em etnologia e tradições orais ameríndias, realiza pesquisa junto aos Marubo do Vale do Javari (AM) desde 2004.

12 Bino Pankararu é líder dos índios Pankararu que vivem no Real Parque, São Paulo, cumprindo função religiosa em sua cultura. Nascido na Aldeia Brejo dos Padres, em Pernambuco.

${ }^{13}$ Eurico Baniwa nasceu na aldeia Baniwa do Rio Içna, do Alto Rio Negro. Formou-se em Filosofia em Manaus, e trabalhou com saúde e educação entre os índios Ianomami. Desde 2004 está em São Paulo, onde estuda Direito e atua no IDET (Instituto das Tradições Indígenas).

14 Juju Mura nasceu no Amazonas, na comunidade Manaquiri, e veio para São Paulo em 2001 para estudar. Formou-se em Pedagogia, fez docência de ensino superior, é professora e divulga a cultura indígena em Cotia-SP.

${ }^{15}$ Poty Porã é guarani, professora indígena, estudou na PUCSP (Pontifícia Universidade Católica de São Paulo) e na USP (Universidade de São Paulo).

${ }^{16}$ Emerson de Oliveria é um índio guarani Nhandeva.
}

Espaço Ameríndio, Porto Alegre, v. 3, n. 1, p. 42-60, jan./jun. 2009. 
DEBORAH GOLDEMBERG - A concepção do I Sarau das Poéticas Indígenas ...

\author{
- Eliane Potiguara ${ }^{17}$. \\ - Graça Graúna ${ }^{18}$. \\ - Olívio Jekupé ${ }^{19}$.
}

\title{
A literatura indianista
}

\author{
- Gonçalves Dias $(1851)^{20}$. \\ - José de Alencar $(1857)^{21}$. \\ - Sousândrade $(1874)^{22}$. \\ - Raul Bopp (1931) ${ }^{23}$. \\ - Mário de Andrade ${ }^{24}$. \\ - Oswald de Andrade ${ }^{25}$. \\ - Douglas Diegues ${ }^{26}$.
}

\footnotetext{
${ }^{17}$ Eliane Potiguara é escritora, professora e ativista indígena. Sua origem é Potiguara, na Paraíba. É coordenadora e fundadora da Rede Grumin de Mulheres Indígenas / Rede de Comunicação Indígena, que ganhou o Prêmio Cidadania Internacional da Comunidade Bahai/IR e diretora do Inbrapi (Instituto Indígena Brasileiro para a Propriedade Intelectual).

${ }^{18}$ Graça Graúna é descendente dos índios Potiguara do Rio Grande do Norte e escritora de ensaios, crônicas e poemas. É graduada, possui especialização, mestrado e doutorado em Letras, tendo dedicadose aos temas de mitos indígenas na literatura infantil e literatura indígena contemporânea no Brasil. Publicou diversos livros, entre os quais o mais recente é Tear da Palavra, de 2007. Mantém um blogue.

${ }^{19}$ Olívio Jekupé escreve poesia desde os 15 anos, cursou filosofia na PUC-PR (Pontifícia Universidade Católica do Paraná) e na USP (Universidade de São Paulo). É escritor de diversos livros indígenas e palestrante. Atualmente, vive na Aldeia Krukutu, em Parelheiros, São Paulo, com sua esposa e quatro filhos.

${ }^{20}$ Gonçalves Dias é considerado o poeta nacional por excelência, tendo conseguido dar vida ao tema do índio na poesia brasileira.

${ }^{21}$ José de Alencar é nascido em Fortaleza, viveu no o Brasil Imperial do Século XIX no Rio de Janeiro e é o grande nome da prosa romântica brasileira. Sua obra indianista inclui alguns de seus romances mais famosos, como O Guarani (1857), Iracema (1865) e Ubirajara (1870)..

${ }^{22}$ Sousândrade, poeta maranhense, viveu no século XIX e recorreu ao multilinguismo para incorporar o elemento indígena amazônico ao seu poema épico $O$ Guesa Errante (1874). Morreu em São Luis, na miséria e considerado louco. Sua obra veio a ser reconhecida por Haroldo e Augusto de Campos na década de 60.

${ }^{23}$ Raul Bopp nasceu no Rio Grande do Sul e viveu no início do século XX. Integrou o grupo paulista do modernismo, cujas correntes verde-amarelas (Pau Brasil) e antropofágicas fez parte. Escreveu sua obraprima, Cobra Norato, sobre a Amazônia.

${ }^{24}$ Mário de Andrade, paulistano, foi líder do movimento modernista brasileiro e promotor da Semana de Arte Moderna em 1922. Pesquisador de etnografia e folclore, seu romance Macunaima é considerado uma das obras capitais da narrativa brasileira no século XX e o fundamento de uma nova linguagem literária.

${ }^{25}$ Oswald de Andrade, paulistano, foi líder do movimento modernista brasileiro e promotor da Semana de Arte Moderna em 1922. É de sua autoria o Manifesto Antropofágico de 1928, que criticava o academicismo da arte brasileira e buscava valorizar a cultura brasileira.

${ }^{26}$ Douglas Diegues é escritor, vive na fronteira do Brasil com o Paraguai e escreve numa linguagem em portunhol selvagem, misto de português, espanhol e Guarani. Tem diversos livros publicados e mantém
}

Espaço Ameríndio, Porto Alegre, v. 3, n. 1, p. 42-60, jan./jun. 2009. 
- Deborah Goldemberg ${ }^{27}$.

- Pedro Tostes ${ }^{28}$.

\section{Referências bibliográficas}

BRANDÃO, Roberto de Oliveira. Introdução. In. ARISTÓTELES et al. A poética clássica: Aristóteles, Horácio, Longino. São Paulo: Cultrix, 1988. p. 1-16.

CESARINO, Pedro. Os poetas. O Estado de São Paulo, São Paulo, 18 jan. 2009. Caderno Aliás. p. 6-7.

DALTON, George. Economic anthropology and developmento: essays on tribal and peasant economies. New York/London: Basic Books. 1971.

DIEGUES, Douglas; SEQUERA, Guilhermo. Kosmofobia Mbya Guarani. São Paulo: Mendonça \& Provazi Editores. 2006.

DIEGUES, Douglas. O portunhol selvagem. Disponível em: http://www.jblog.com.br/ideias.php?itemid=5064 . Acesso em: 25 jun. 2009.

GEERTZ, Clifford. The interpretation of culture. New York: Basic Books, 1973.

MAIAKOVSKI, Vladimir. Poética: como fazer versos. São Paulo: Global, 1977.

MOORE, Henrietta L. A passion for difference. Cambridge: Polity Press, 1994.

MUNDURUKU, Daniel. Literatura indígena e o tênue fio entre escrita e oralidade. Disponível em: http://www.overmundo.com.br/overblog/literatura-indigena. 2008 . Acesso em: 25 jun. 2009.

PREZIA, Benedito. Indígenas em São Paulo: ontem e hoje. São Paulo: Paulinas, 2001.

\footnotetext{
um blog.

${ }^{27}$ Deborah Goldemberg, paulistana, é antropóloga e escritora de histórias transbrasileiras e multiétnicas. Tem crônicas, poemas, um livro publicado e mantém um blog literário.

${ }^{28}$ Pedro Tostes, carioca, indiodescendente e poeta do movimento paulistano de poesia maloqueirista.
}

Espaço Ameríndio, Porto Alegre, v. 3, n. 1, p. 42-60, jan./jun. 2009. 